\title{
South African Journal of Business Management: Annual editorial overview 2020
}

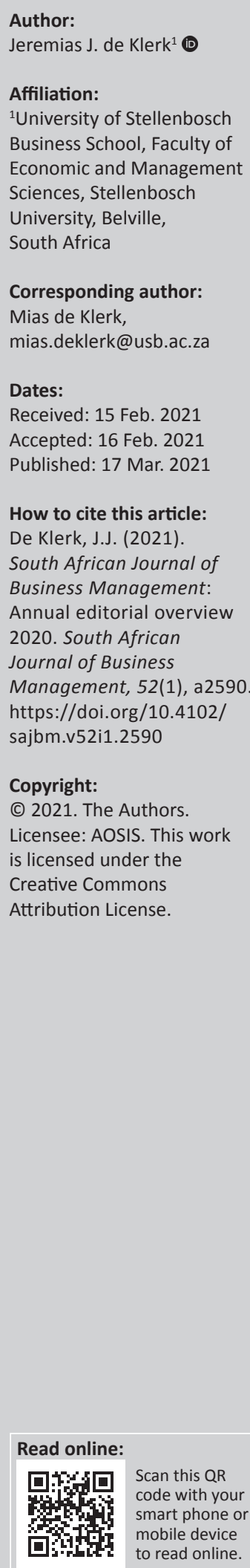

\section{Introduction}

It is with great pride that I welcome you to the 2020 volume of the South African Journal of Business Management (SAJBM). More than a year has passed since moving to African Online Scientific Information Systems (AOSIS) as publisher, and moving from a printed journal early in 2018 to a journal that is exclusively published as an online journal. The theme of this annual review is the celebration of the success of the SAJBM over the past few years.

\section{Journal quality}

Since the SAJBM's inception, the journal continues to be recognised internationally as a leading-edge, accredited journal for publishing quality research in the field of business science. The SAJBM provides cutting-edge, peer-reviewed research in all fields related to the vast complement of business science. The metrics and accreditation listings of the SAJBM, including Web of Science, Chartered Association of Business Schools, Scopus, Australian Business Deans Council, EBSCOHost, Directory of Open Access Journals and the Norwegian Register for Scientific Journals and Scimago, confirm the international recognition of the journal. However, just being listed by these agencies is not sufficient. The competition for high-quality research amongst journals is fierce, and unless a journal consistently improves, it will become redundant. The output of journals is measured by several metrics to provide a comprehensive perspective on the quality of a journal and to continue to be listed by accreditation agencies. It thus gives me great pleasure to report that the SAJBM has improved significantly on the important metrics over the past 3 years:

- The Web of Science h-index (Journal Impact Factor) increased from 0.28 in 2017 to 0.44 in 2020. This reflects a $57 \%$ improvement.

- The Scopus Source Normalised Impact per Paper score (SNIP) improved from 0.307 in 2017 to 0.417 in 2020 - a 36\% improvement.

- The percentage of published articles cited increased from $32 \%$ in 2017 to $45 \%$ in 2020 - a $41 \%$ improvement.

- The CiteScore improved from 0.7 in 2017 to 0.9 in 2020 - a $29 \%$ improvement.

These metrics provide evidence of the quality and stature of the SAJBM. It also confirms the rigour of our double-blind, peer-review processes in ensuring the publication of high-quality, scientific material with impact and practical application. Researchers increasingly look for journals with international ratings to publish their research. The standing that the SAJBM receive in the international scientific community is improving and the excellent performance on the metrics noted above resulted in increasing interest from authors to publish their research in the SAJBM. This is evident in the 465 submissions received for consideration in 2020, which is an increase of $26 \%$ from 2019.

Such an achievement does not come easily and will not be possible without the contributions of dedicated authors and reviewers. Firstly, I would like to thank researchers who selected the SAJBM as their journal of choice to publish their articles. We appreciate the confidence that you put in the SAJBM and will endeavour to remain worthy of your support. Secondly, I want to sincerely thank our reviewers who spend much time reviewing the large number of manuscripts submitted to the SAJBM. Reviewing is a largely thankless service that scientists do to improve their field of science. Without this dedication, publications will not be possible.

Maintaining the journal's quality at a high standard often means that many manuscripts, submitted to the SAJBM for consideration, do not make it to publication. Unfortunately, $72 \%$ (335) 
of the manuscripts were desk rejected during this period. In other words, the manuscripts were declined by the editor-inchief, without sending it for peer review. Of the 130 manuscripts that were sent for external review, another $71 \%$ were rejected. Eventually, 29 high-quality articles were accepted, of which 25 were published in 2020, the other four will be published early in 2021 .

The rejection rates may appear to be quite high and may be perceived as harsh. Being an author myself, I am truly aware of the disappointment and emotional turmoil one goes through when one's manuscript is declined, especially when this is done without peer review. However, there are good reasons to be frugal when considering new submissions. Firstly, we have to honour the effort of our team of reviewers who selflessly dedicate their time to review the manuscripts as a free service to the scientific community. The editor has to ensure that the reviewers' time is not misused unnecessarily on manuscripts that are, from the beginning, unlikely to obtain a favourable review. Furthermore, to keep our international rankings and standings, we have no choice but to only accept the very best of the submissions for publication.

To avoid desk rejection, my best advice to prospective authors is to study the submission guidelines carefully; make sure you have done professional editing of your manuscript and ensure clarity of writing throughout; make sure your literature study is scientifically sound and comprehensive, applying rigour in the scientific method and its description. Lastly, remember that the concluding section of your research is very important and should be far more than a mere summary of the study. For instance, the authors have to highlight the practical impact of the research on business. Also, as all research studies have limitations, it is essential to acknowledge the limitations of the research and suggest recommendations for future research - beyond the obvious.

\section{Our review process}

We understand that all authors would like to get feedback on their submissions as soon as possible and expect a limited period until publication, if the manuscript was accepted. The most critical challenge is probably to find suitably qualified and willing referees, as the volume of papers submitted tend to increase from year to year. The availability of competent reviewers has a notable impact on the turnaround time of submissions to the SAJBM. To relieve the workload of our reviewers, another 120 additional reviewers were registered during 2020. Nevertheless, as we all know, 2020 was a particularly difficult year for most of us because of the challenges presented by coronavirus disease 2019 (COVID-19). Although we are still busy gathering the data, it appears thatthe SAJBM, as many other similar journals, struggled to get reviewers who were willing to do a review or to obtain quick responses from reviewers in this difficult time.

We continually strive to reduce the time from submission to publication. Without the double-blind peer review process, we will not be able to maintain our international accreditations. New contributors of papers to the SAJBM have proven to be a trustworthy source of new referees in certain subject areas where critical shortages are developing. I would, therefore, like to encourage our authors and readers to make yourselves available for review, if approached for this task. As scientists and authors, we are all dependent on getting our work published and being reviewed by other scientists. It is, therefore, every scholar's duty to return this favour and act as a peer reviewer for others.

\section{Ethical publication}

Publication ethics forms an integral part of the pre-screening and peer-review processes. African Online Scientific Information Systems is a member of CrossCheck plagiarism detection initiative and endorses and applies the standards of the Committee on Publication Ethics (COPE) which promotes integrity in peer-reviewed research publications. The SAJBM is also a member of COPE and the editors make use of iThenticate software for checking the originality of submissions received. Submissions that do not conform to acceptable originality standards are not considered for peer review. Indeed, all submissions that pass the editorial review are assessed for similarity with published material through iThenticate. The iThenticate report of every submission is scrutinised and unfortunately, we had to reject several submissions because of unacceptably high semblance with previously published material. Information on the peer-review and ethics practices applied by the SAJBM publication process is available on the journal's website.

\section{Overview of article topics: South African Journal of Business Management, volume 51 (2020)}

It remains an explicit aim of the SAJBM to promote and publish research with impact. The range of articles published in the 51st volume of the SAJBM does not only demonstrate the growing international stature of the journal, but also its coverage of the broad field of business science. The articles explore a large variety of interesting topics from quite diverse fields, which are of relevance to the world of business today. For instance, the articles range from leadership to marketing, governance to coaching, entrepreneurship to tax and finance, economics to organisational behaviour, and operations to innovation and technology.

The SAJBM provides the opportunity to showcase your research and contribute to the growing body of scientific knowledge about the science and art of business management. I trust that you will find the articles in this volume to be insightful and useful as with previous volumes. In our continued endeavour to improve our offering to you, we really would appreciate any feedback that you may have. 


\section{In conclusion}

The successful annual publication of the SAJBM volume is not a distinction attributable to the Editor-in-Chief alone. Rather, it is a collaborative team effort. I would like to express my gratitude to the scholarly and scientist-practitioner community, who make use of our articles, either in practice or by incorporating them into their scholarly endeavours. I also would like to extend a heartfelt 'thank you' to all authors for their respective contributions in ensuring that the SAJBM remains representative of the developments in business and management science. But the biggest 'thank you' must go to the reputable and committed team of scholarly peer reviewers. Our reviewers selflessly give their time and energy to review the submissions; ensuring the publication of high-quality articles, and they do so without reward and often after-hours. Thank you so much, you are the stars and the cornerstone of the success of the SAJBM. Last, but not the least, I would like to thank Dr Lara Skelly, the Managing Editor, for the commitment and support from an amazingly accomplished AOSIS staff. A huge word of thanks to everyone in the management and administration of SAJBM for your cooperation and hard work in ensuring this success.

I am excited about the future of the SAJBM and believe that the significant collaborative efforts we annually experience within our community of scientists, practitioners and supporting staff will help to further advance the field of business and management science to the benefit of individuals, organisations and society as a whole.

Prof. Mias de Klerk

Editor-in-Chief

South African Journal of Business Management 